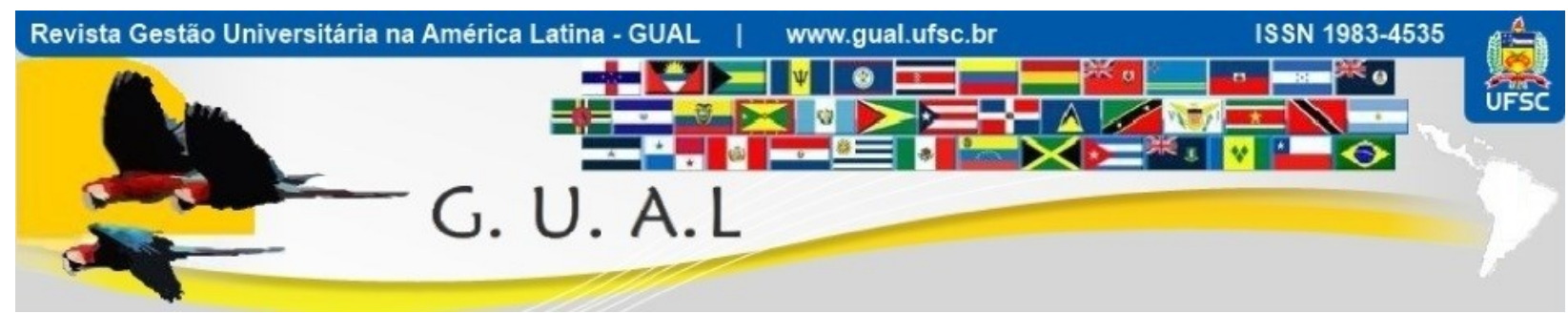

DOI: http://dx.doi.org/10.5007/1983-4535.2017v10n4p327

\title{
O PAPEL DO PROFESSOR-GESTOR EM UMA INSTITUIÇÃO FEDERAL DE ENSINO SUPERIOR DE ALAGOAS: UM ESTUDO NA UFAL/CAMPUS ARAPIRACA
}

THE ROLE OF ACADEMIC-MANAGER IN A FEDERAL INSTITUTION OF HIGHER EDUCATION OF ALAGOAS: A STUDY AT UFAL - CAMPUS ARAPIRACA

Maria Marques dos Santos Magalhães, Graduada Universidade Federal de Alagoas - UFAL mariamsmadm@gmail.com

Milka Alves Correia Barbosa, Doutorado Universidade Federal de Alagoas - UFAL milka.correia@gmail.com

José Rodolfo Tenório Lima, Mestre Universidade Federal de Alagoas - UFAL jrtlima@gmail.com

Fernanda Roda de Souza Araújo Cassundé, Doutora Universidade Federal do Vale do São Francisco - UNIVASF fernandaroda@gmail.com

Recebido em 25/novembro/2016

Aprovado em 16/outubro/2017

Sistema de Avaliação: Double Blind Review

Esta obra está sob uma Licença Creative Commons Atribuição-Uso. 


\title{
RESUMO
}

Os docentes são os responsáveis pela gestão da universidade, por meio de práticas gerenciais, decisões e ações que viabilizam o alcance dos objetivos organizacionais. O propósito da presente pesquisa foi caracterizar o papel do professor-gestor na UFAL/Campus Arapiraca. O referencial teórico do trabalho foi composto de temas como papel de professor de ensino superior, gestão universitária e papel de professor-gestor. Trata-se de um estudo de caso de cunho qualitativo e exploratório. Para alcançar o objetivo proposto foram realizadas cinco entrevistas com professores, baseadas em um roteiro semiestruturado, as quais foram gravadas e transcritas. A Análise de Conteúdo foi adotada para análise dos dados. Os dados coletados mostraram que ao assumir o papel de gestor na IFES, o professor não possui uma preparação para a atividade administrativa e que esse aprendizado acontece durante o exercício do papel. No que se refere à construção do papel de gestor, observa-se que este processo se dá cotidianamente, baseando-se em experiências individuais e entre erros e acertos. Como também, os grupos que interagem com os gestores dão suporte para que eles desempenhem as atividades e assim também colaboram para construção do papel de professor-gestor.

Palavras chave: Instituição Federal de Ensino Superior (IFES); professor de ensino superior; gestão universitária; professor-gestor.

\begin{abstract}
Teachers are responsible for the management of the university, through management practices, decisions and actions that enable the achievement of organizational objectives. The aim of this research was to characterize the role of academic-manager at UFAL / Campus Arapiraca. The theoretical reference of the work was composed by themes such as the role of the teacher at higher education, the university management and the role of academic-manager. It is a qualitative and exploratory case study of. To reach the objective proposed, five interviews semi structured were conducted with teachers and, then they were transcribed. The Content Analysis was adopted to analyze the data. The data collected showed that, in assuming the role of manager in a federal institution of higher education (FIHE), the teacher does not have a preparation for the administrative activity and that this learning happens during the exercise of the role. With regard to the construction of managerial role, it is observed that this process happens daily, based on individual experiences and between errors and successes. As else as, groups that interact with managers support them to activities and thus also collaborate to build the role of academic-manager.
\end{abstract}

Keywords: Federal Institution of Higher Education (FIHE). Teacher of Higher Education. University Management. Academic-Manager. 


\section{INTRODUÇÃO}

Atualmente, o trabalho do professor de ensino superior não está mais voltado apenas para o ensino em sala de aula, a universidade tornou-se não só um lugar para aprender e se profissionalizar, é também pesquisa e desenvolvimento tecnológico e humano, é instituição de captação de recursos para construção de saber.

Nesse cenário, o perfil dos professores de ensino superior como detentores de saberes, destreza e conhecimento tem sido modificado frente a massificação do ensino superior, a interiorização das Instituições Federais de Ensino Superior e o aumento do número de Instituições Federais de Ensino Superior (IFES).

No Brasil, em 2003, o governo inicia um projeto para expandir o ensino superior público com o Programa de Reestruturação e Expansão das Universidades Federais (REUNI), este que tem o objetivo principal de ampliar o acesso e a permanência na educação superior, segundo site do Ministério da Educação e Cultura (MEC, 2006).

O MEC afirma que, com as ações propostas pelo REUNI, houve o aumento de vagas no curso de graduação e o aumento de oferta de cursos noturnos. O REUNI foi instituído pelo Decreto $\mathrm{n}^{\circ}$ 6.096, de 24 de abril de 2007, e é uma das ações que integram o Plano de Desenvolvimento da Educação (PDE). No ano de 2007, das 54 instituições federais inscritas 53 aderiram ao programa, em 2007 o número de vagas ofertadas para graduação era de 147.277 e em 2008 conseguiu um aumento equivalente a 14.826 vagas (MEC, 2009).

A interiorização das Universidades através do Programa de Reestruturação e Expansão das Universidades Federais (REUNI) se caracterizou como uma ação do Ministério da Educação que pretendia a partir do ano de 2008 dobrar a quantidade de ingressos em Instituições de Ensino Superior (IES), no prazo de 10 anos.

Diante desse cenário de massificação do ensino superior, podemos afirmar que cada vez mais o papel do professor foi se adaptando a nova realidade. Outras funções têm sido agregadas, tornando o exercício profissional do professor de ensino superior ainda mais complexo (BARBOSA, 2015). Com efeito, houveram alterações no trabalho do professor, ampliando-se os papéis comumente associados a esses profissionais, notadamente o de docente, o de pesquisador, o de extensionista, em virtude do aprofundamento da cultura do desempenho, que denota a supervalorização do conhecimento como uma nova forma de acumulação de capital. 


\section{O PAPEL DO PROFESSOR-GESTOR EM UMA INSTITUIÇÃO FEDERAL DE ENSINO SUPERIOR DE \\ ALAGOAS: UM ESTUDO NA UFAL/CAMPUS ARAPIRACA \\ DOI: http://dx.doi.org/10.5007/1983-4535.2017v10n4p327}

Importa aqui delimitar que falar em papéis sociais significa reconhecer que certas atividades e tarefas são esperadas de um indivíduo dentro de organização em determinada posição, como, por exemplo, em uma IFES, em uma universidade (BARBOSA, 2015).

No Brasil, a atuação dos professores das IFES é fortemente norteada pela Lei das Diretrizes e Bases da Educação Nacional (LDB) instituída em 1996 e Diretrizes Bases Nacionais (DBN) em 2001. Destaque-se também o Art. $3^{\circ}$ do Decreto n ${ }^{\circ}$ 94.664\87 (BRASIL, 1987) prevê a gestão universitária como uma atividade do professor do ensino superior, juntamente com o ensino, a pesquisa e a extensão. Nesse contexto, o professor ao assumir um cargo de gestão passa a exercer as duas funções: a de professor e a de gestor.

Quando o professor atua no papel de gestor, quer seja como reitor ou pró-reitor, por exemplo, entra em cena o papel de professor-gestor - aquele no qual o professor ou pesquisador desempenha papel de gestor no ensino superior, seja temporariamente ou permanentemente (CASTRO; TOMÀS, 2011). Ou seja, mesmo assumindo a posição de dirigente, esse indivíduo não deixa de ser professor (ÉSTHER, 2007) e, portanto, a dupla atividade constitui o cerne do papel de professor-gestor.

Diante das modificações nos papéis dos professores e a ênfase do papel de gestor, a pergunta de pesquisa é: como se caracteriza o papel do professor-gestor na Universidade Federal de Alagoas (UFAL)/Campus Arapiraca?

O presente estudo buscou provocar reflexões sobre os papéis do professor hoje nas IFES, com destaque para o papel de professor-gestor. Nesse sentido, destaque-se que se trata de uma pesquisa pioneira na UFAL/Campus Arapiraca, inspirada em estudos na mesma área (SILVA, 2012; SILVA; CUNHA，2012; BARBOSA, 2015; BARBOSA; CASSUNDÉ; MENDONÇA, 2015), porém em instituições diferentes.

Como também, este trabalho buscou aproximar as definições e as expectativas diante do professor de ensino superior focando no papel de gestor, quando se propõe ao estudo dos papéis sociais dos professores nas IFES.

No cenário nacional, a presente pesquisa insere-se no conjunto de estudos como os de Barbosa (2015), Silva (2012) Paiva (2007) entre outros, que retratam a ampliação dos papéis do professor de ensino superior mostrando que as atividades desses sujeitos vão além da tríade ensino-pesquisa-extensão. À nível local, o estudo mostra-se importante para o ensino superior de Alagoas por ser pioneiro e buscar expandir os limites do conhecimento acerca do professor que assume o papel de gestor nas IFES. Voltando o olhar para o Agreste do Estado, 
onde está situada a UFAL/Campus Arapiraca, a pesquisa é importante, pois apresenta como algumas das limitações e peculiaridades desse cenário incidem no papel de professor-gestor.

Encerrados os aspectos introdutórios, no próximo capítulo serão apresentados os temas que deram suporte à pesquisa.

\section{OS PAPÉIS DO PROFESSOR DE ENSINO SUPERIOR}

Antes de abordar o papel do professor de ensino superior, convém discutir brevemente acerca do construto papel social.

Os papéis sociais existem em qualquer cenário, seja ele, família ou instituição e sua origem encontra-se no processo fundamental de formação de hábitos e objetivação que as origens de instituições (BERGER; LUCKMANN, 2005).

É possível identificar pelo menos duas abordagens distintas sobre papel, cercadas em ambiguidade e disputas sobre terminologias - a sistêmica e a construtivista. A primeira considera o comportamento individual como uma série de sistemas de papel localizado dentro de um contexto organizacional. Baseando-se em conceitos como input, output, processamento, o desempenho do papel é definido na dinâmica entre expectativas de papel, papel enviado, papel recebido e comportamento no papel. Como consequência, há sempre um ciclo contínuo de enviar, receber e responder a expectativas de comportamento que são usadas para avaliar as ações de qualquer indivíduo que ocupe determinada posição na organização. Portanto, papel reflete um conjunto de expectativas sociais e comportamentos normativos que prescrevem como um indivíduo deveria ocupar determinada situação, posição ou status social.

Para o segundo grupo de abordagens, o papel é visto como um processo contínuo de construção social que depende da inter-relação entre uma ordem social estática e previsível e as ações criativas dos atores (BERGER; LUCKMANN, 2005).

Em virtude dos papéis que desempenha, o indivíduo é introduzido em áreas específicas do conhecimento socialmente objetivado, não somente no sentido cognoscitivo estreito, mas também no sentido de "conhecimento" de normas, valores e mesmo emoções (BERGER; LUCKMANN, 2005).

Cabe ainda esclarecer que os papéis comportam três aspectos: o que se espera que os sujeitos façam (definição do papel ou papel esperado), como eles interpretam e constroem o seu papel (papel percebido) e o que eles realmente fazem no decurso do seu trabalho (comportamento ou performance no papel - papel realizado) (HALES, 2005). Vale ressaltar 
que o alinhamento exato entre esses três tipos é algo pertencente ao campo das ideias, dificilmente alcançado na realidade das organizações, havendo, provavelmente um hiato entre o papel esperado, o papel percebido e o papel realizado, com possibilidade de conflito e frustração, resultantes das diferenças nestes três tipos.

Em se tratando de papéis sociais do professor de ensino superior, diante de todas as transformações e expansão sofridas nas últimas décadas, novas demandas e expectativas foram atreladas. Assim, partilhando do pensamento de Cardoso e Figueiredo (2013), Barbosa (2015), os papéis do professor nas IFES passaram a ter uma abordagem diferente, assumindo outros para além dos mais centrais o de docente, o de pesquisador, o de extensionista e o de gestor, comumente reportados na literatura especializada (BARBOSA; CASSUNDÉ; MENDONÇA, 2015).

Já Mendonça et al. (2012) lembram que as atividades acadêmicas de nível superior mudaram significativamente nas últimas décadas, entendendo-as em cinco esferas: ensino, pesquisa, extensão, orientação e administração. As atividades propostas por esses autores ampliam a tríade contemplada na Lei de Diretrizes e Bases da Educação Nacional (LDB) ensino, pesquisa e extensão - e incluem atividades de cunho administrativo e burocrático, nas quais se caracterizam como ações de gestão (MENDONÇA et al., 2012).

Caracterizando especificamente os papéis do professor de universidade federal, Franco (2000) descreve-o como que aquele trabalha em uma complexa instituição, com um sistema de pós-graduação e grupos de pesquisa devidamente normatizados por instâncias como Conselho Nacional de Desenvolvimento Científico e Tecnológico (CNPq), Coordenação de Aperfeiçoamento de Pessoal de Ensino Superior (Capes), entre outros. É, também, o sujeito que trabalha em uma IES ancorada no seu meio social, na qual o ensino é a própria razão de ser (ÉSTHER, 2008).

Esse professor tem um plano de trabalho com horários voltados à pesquisa, mas é demandando por tantas horas em ensino que não sobra espaço para investigações, e não raramente acumula grande carga horária de atividades em sala de aula. Em seu cotidiano, esse indivíduo vive as tensões próprias da sua área de conhecimento, frequentemente impregnada pelo corporativismo, e lutas por espaços e financiamentos dentro desse espaço político, que é a universidade federal.

De fato, reconhece-se que nas últimas décadas novos desafios e pressões foram colocados aos professores de ensino superior, em especial àqueles que atuam em IFES, dentre 
eles a preocupação com a massificação do ensino superior, com o declínio no status socioeconômico do ensino superior devido à sua expansão (PACHANE; PEREIRA, 2004).

Em 2003, o Governo Federal iniciou um projeto para expandir o ensino superior público com o REUNI, e a partir disso, foram criadas quatorze universidades públicas aumentando significativamente o número de ofertas de vagas para o ensino superior. Já no ano de 2007, 53 IFES aderiram ao REUNI com vistas a alcançar o objetivo de dobrar o número de vagas ofertadas para o ensino superior.

Nessa nova dinâmica, atividades que antes eram consideradas secundárias ou periféricas pelo professor de ensino superior hoje são reconhecidas por sua importância, notadamente as atividades de gestão. No Brasil, o Art. $3^{\circ}$ do Decreto 94.664/87 (BRASIL, 1987) prevê a gestão universitária como uma atividade do professor do ensino superior, juntamente com o ensino, a pesquisa e a extensão. Sendo assim, na seção seguinte será apresentado o papel de professor-gestor.

\section{O PAPEL DO PROFESSOR-GESTOR}

Mais do que possibilitar a formação integral dos estudantes, o gestor universitário, , precisa ter a capacidade de refletir sobre as necessidades e os objetivos da instituição, compreendendo sua função social como educador (CERVIGICELE; SOUZA, 2013).

Nesse sentido, a legislação brasileira, por meio do Art. $3^{\circ}$ do Decreto $n^{\circ} 94.664$ de 23 de julho de 1987, considera atividades acadêmicas próprias do docente de ensino superior: "I - as atividades pertinentes à pesquisa, ensino e extensão [...]; II - as inerentes ao exercício de direção, assessoramento, chefia, coordenação e assistência na própria instituição, além de outras previstas na legislação vigente" (BRASIL, 1987, p. 39-40).

$\mathrm{O}$ papel de professor-gestor se caracteriza pela complexa tarefa de fomentar, incentivar e gerenciar os mecanismos de desenvolvimento organizacional, sem deixar de considerar as atividades relacionadas ao tripé ensino, pesquisa e extensão. Como também, o papel de professor-gestor lida com expectativas internas e externas, conflitos, demandas e ideologias que por vezes mostram-se incompatíveis ou contraditórias (BARBOSA; CASSUNDÉ; MENDONÇA, 2015).

Autores como Meyer Jr (2003), Barbosa, Cassundé, Mendonça (2015) partilham a mesma ótica de que, cada vez mais, a divisão entre academia e administração está menos visível e que ganharam destaque alguns profissionais que transformaram a universidade em 
uma organização multiprofissional (WHITCHURCH, 2012), dentre eles os professoresgestores (academic managers): aqueles professores que atuam em papéis de gestão (BARBOSA; CASSUNDÉ; MENDONÇA, 2015).

Pode-se considerar que um dos primeiros desafios com os quais o professor se depara ao assumir trabalho gerencial nas IFES é a escolha entre trabalho acadêmico e trabalho administrativo (BARBOSA, 2015), o que inclui ter que lidar, ao mesmo tempo, com as demandas gerenciais e com o interesse local de sua unidade de ensino.

Outra demanda direcionada ao professor-gestor refere-se ao alcance das expectativas de que esses indivíduos compreendam e aceitem novas responsabilidades e atividades, e aprendam a lidar com os mais diversos desafios da atividade gerencial. No mundo acadêmico, em especial nas IES, é comum, somarem-se às atividades de ensino, pesquisa e extensão as atividades de gestão universitária, e, portanto, muito raramente o professor abre mão de suas atividades tidas como principais para dedicar-se mais exclusivamente às funções de gestor (SILVA, 2012).

Como também, pode-se dizer que ao assumir o papel de gestor, o professor da IFES torna-se responsável não somente por seus alunos e suas pesquisas; o "ser gerente" implica também a coordenação de seus pares e a regulação de conflitos, entre outras responsabilidades (MARRA, 2006).

Importa ainda destacar que se espera do gestor universitário continuar contribuindo para formação integral dos estudantes, exercendo sua função social como educador (CERVIGICELE; SOUZA, 2013).

Outro desafio enfrentado pelo professor-gestor é a falta de preparação para assumir o cargo de gestão, [...] "na maioria dos casos, não antecedem treinamento formal à atuação dos indivíduos escolhidos para as funções gerenciais na universidade. Isto faz com que adquiram condições de atuar como gestores, pelo método da tentativa e do erro" (CAMPOS, 2007, p. 2). Alinhando-se à essa perspectiva, o estudo de Silva e Cunha (2012) ressalta que nas atividades do professor-gestor prevalecem a improvisação, o imediatismo, a falta de planejamento, características essas condizentes com a literatura já apresentada que discute as atividades dos gerentes contemporâneos.

De fato, os professores-gestores desempenham papéis complexos e distintos nas universidades. Podem-se apontar alguns deles tais como o de atender as necessidades de vários atores, incluindo estudantes, pares, sociedades, membros de colegiados, entre outros. 
(BARBOSA; CASSUNDÉ; MENDONÇA, 2015). Diante de tal complexidade, o professorgestor está diretamente ligado ao desenvolvimento da IFES, através de alocação de recursos, mediação de conflitos e planejamento estratégico.

Pode-se afirmar que na universidade é fortemente presente o aspecto da temporalidade do exercício do cargo de gerência. O docente pode, ao longo de sua carreira universitária, assumir uma coordenação de curso, uma chefia de departamento, pró-reitoria ou reitoria. Após essa experiência, ele pode retornar à sua função original, o que, na maioria das vezes, significa voltar a ser professor, sem as responsabilidades típicas da gestão universitária. Não obstante o fato de essas transições serem rotineiras nas universidades, elas merecem maior compreensão (SILVA; CUNHA, 2012).

Ou seja, o professor-gestor de uma universidade estabelece interações e relações com outros indivíduos e grupos, mantendo similaridades e diferenças quanto às competências gerenciais, às expectativas sobre seu desempenho no papel, aos desafios com os quais se deparam no cotidiano organizacional (BARBOSA, 2015).

Após apresentar os temas que compõem o referencial teórico, o próximo capítulo apresentará a metodologia usada na pesquisa.

\section{METODOLOGIA}

Aqui são apresentados os aspectos metodológicos relacionados à presente investigação, tais como tipo de pesquisa, sujeitos da pesquisa, lócus da pesquisa, método de coleta de dados e a técnica de análise dos dados.

\subsection{DELINEAMENTO DA PESQUISA}

A presente pesquisa pode ser classificada como qualitativa, por se tratar de uma investigação que aborda aspectos dificilmente quantificáveis, como a caracterização do papel social de gestor desempenhado pelos professores na UFAL/Campus Arapiraca. Segundo Bauer e Gaskel (2002) a pesquisa qualitativa evita números, lida com interpretações das realidades sociais. Além disso, é muitas vezes vista como uma maneira de dar poder ou dar voz as pessoas, em vez de tratá-las como objetos, cujo comportamento deve ser quantificado e estatisticamente modelado (BAUER; GASKELL, 2002).

De outra perspectiva, a presente pesquisa também pode ser caracterizada como exploratória, pois buscou esclarecer o papel de professor-gestor na IFES, um estudo ainda não 
realizado na UFAL/Campus Arapiraca. Para Gil (2008) estudo exploratório é um estudo que tem como principal finalidade desenvolver, esclarecer e modificar conceitos e ideias, tendo em vista a formulação de problemas mais precisos ou hipóteses pesquisáveis para estudos posteriores. Elas são desenvolvidas como objetivo de proporcionar visão geral, de tipo aproximativo, acerca de determinado fato (GIL, 2008).

Pode-se classificar esta investigação ainda como um estudo de caso básico caracterizado pelo estudo profundo e exaustivo de um ou de poucos objetos, de maneira a permitir o seu conhecimento amplo e detalhado, tarefa praticamente impossível mediante os outros tipos de delineamento considerados (GIL, 2008).

\subsection{PARTICIPANTES DA PESQUISA}

Para a definição dos participantes do estudo não houve a preocupação em alcançar uma quantidade ideal de sujeitos, tendo em vista que a diretriz orientadora era escolher aqueles capazes de desenvolver alguma relação significativa com o fenômeno em estudo. Desta forma, foram entrevistados os indivíduos que constituíam o grupo considerado relevante para responder à questão de pesquisa (SCHWANDT, 2007), sendo possível afirmar que eles foram escolhidos de acordo com o critério da tipicidade (GASKELL, 2010).

O grupo é composto por professores-gestores de nível estratégico, que desempenham ou desempenharam o papel de professor-gestor no Campus Arapiraca nos últimos 10 anos, um período no qual o ensino superior vem ganhando evidência devido ao processo de interiorização e seu desenvolvimento, destacando-se nesse cenário a importância do papel de professor-gestor para a consecução das políticas de ensino superior.

\subsection{LÓCUS DA PESQUISA}

A pesquisa teve como lócus a Universidade Federal de Alagoas/Campus Arapiraca, situada no agreste do estado de Alagoas, criada em 2006 através do REUNI, que tem o objetivo principal de ampliar o acesso e a permanência na educação superior. No projeto de interiorização das IFES, em Alagoas, a UFAL foi contemplada com um campus no agreste do Estado.

A UFAL/Campus Arapiraca oferta hoje 20 cursos, que atendem à demanda da população ativa que busca ter ensino superior. A instituição foi escolhida como campo de 
pesquisa por ser referência em ensino superior na região do Agreste de Alagoas, sendo de relevância estratégica para a política de expansão do ensino superior.

\subsection{COLETA DE DADOS}

Em consonância com a perspectiva qualitativa da pesquisa, foram realizadas cinco entrevistas semiestruturadas para a coleta de dados. A entrevista semiestruturada é uma série de perguntas abertas, feitas oralmente em uma ordem prevista, mas na qual o entrevistador tem a possibilidade de acrescentar questões de esclarecimento (LAVILLE; DIONNE, 1999).

As principais vantagens desse tipo de entrevista são a possibilidade de o entrevistador poder perguntar algo que tenha sido motivado pelo discurso do entrevistado, mesmo que esta questão não esteja em seu roteiro; a adaptação da maneira de perguntar de acordo com o entrevistado; a roupagem da entrevista semiestruturada é mais de uma conversa; flexibilidade do tempo, como relatam Laville e Dione (1999), Bauer e Gaskell (2002), Gil (2008).

Ao iniciar as entrevistas, os pesquisadores solicitavam a autorização para que esta fosse gravada. Foi utilizado um aparelho celular para registrar todas as entrevistas. Nenhum dos entrevistados negou-se a gravar a entrevista ou interrompeu a mesma. As entrevistas foram realizadas em março/2016, tiveram duração em média de 20,4 minutos, totalizando aproximadamente 102 minutos. No interesse da confidencialidade, os nomes dos entrevistados foram resguardados, sendo os mesmos identificados apenas como professoresgestores (PG). As entrevistas foram analisadas e transcritas à medida que iam sendo realizadas.

\subsection{CATEGORIAS DE ANÁLISE}

No planejamento da pesquisa são definidas categorias que orientam a coleta, análise e interpretação dos dados (GIL, 2008). Tomando por base a análise feita no presente trabalho, as categorias de análise foram definidas a priori, antes mesmo de iniciarem as entrevistas e foram baseadas na pergunta de pesquisa, no referencial teórico desenvolvido. Nesse sentido, na presente investigação as categorias foram as seguintes: papel percebido, trajetória no papel de professor-gestor, construção do papel do professor-gestor e influência dos grupos na construção do papel de professor-gestor. 
Quadro 1 Categorias de análise definidas a priori

\begin{tabular}{|l|l|}
\hline \multicolumn{1}{|c|}{ Categoria de Análise } & \multicolumn{1}{|c|}{ Definição Construtiva } \\
\hline Papel Percebido & $\begin{array}{l}\text { Descreve como os professores de ensino superior } \\
\text { percebem as atividades e expectativas que compõem o } \\
\text { papel de gestor. }\end{array}$ \\
\hline $\begin{array}{l}\text { Trajetória no Papel de } \\
\text { Professor-gestor }\end{array}$ & $\begin{array}{l}\text { Refere-se ao conjunto de aspectos relacionados à carreira } \\
\text { do professor de ensino superior no âmbito da IFES e do } \\
\text { Serviço Público Federal que contribuem para a } \\
\text { construção e o desenvolvimento do papel de professor- } \\
\text { gestor }\end{array}$ \\
\hline $\begin{array}{l}\text { Construção do Papel do } \\
\text { Professor-gestor }\end{array}$ & $\begin{array}{l}\text { Caracteriza o papel que o professor de ensino superior } \\
\text { desempenha na gestão de IES, seja temporariamente ou } \\
\text { permanentemente, a dupla atividade constitui o cerne do } \\
\text { papel de professor-gestor. }\end{array}$ \\
\hline $\begin{array}{l}\text { Influência dos Grupos na } \\
\text { Construção do Papel de } \\
\text { Professor-gestor. }\end{array}$ & $\begin{array}{l}\text { Construção do papel de gestor, diante dos vários grupos } \\
\text { com os quais o professor interage. }\end{array}$ \\
\hline
\end{tabular}

Fonte: Elaborado pelos autores (2016)

\subsection{TÉCNICA DE ANÁLISE DE DADOS}

A técnica de análise utilizada para tratar os dados coletados foi análise categorial, técnica classifica por Bardin (2011), que consiste no desmembramento e reagrupamento do texto em categorias ou temas analógicos.

\section{APRESENTAÇÃO E ANÁLISE DOS DADOS}

Nesta etapa são apresentados e analisados os dados coletados buscando responder à pergunta de pesquisa do presente trabalho.

\subsection{O PAPEL DE PROFESSOR-GESTOR: TRAJETÓRIA E SEU COTIDIANO}

Nas entrevistas, os dados coletados mostram que os PGs entrevistados têm uma longa trajetória até chegarem a uma IFES e a assumirem um cargo de gestão, como expressam alguns professores em sua fala a seguir:

Fiz quatro anos de biologia, em seguida entrei logo no mestrado, fiz o meu mestrado em praticamente 1 ano e 3 meses, fiquei um tempo trabalhando já com educação, em seguida entrei no doutorado. Então aqui na universidade já estou há dez anos e nesses 10 anos foram todos em cargo de gestão (PG1). Em relação a UFAL, antes de eu vir pra UFAL, eu trabalhei aproximadamente uns 10 a 12 anos numa instituição particular. Em 2008 eu vim aqui pra UFAL, são 8 anos de UFAL (PG3). 
$\mathrm{Na}$ realidade eu entrei aqui em 2008.2, em agosto de 2008. [...] Eu sou engenheiro agrônomo, mas entrei pela biologia, porque eles abriram concurso e passei (PG4).

Como pode ser percebido nas falas dos entrevistados, a carreira de professor é uma carreira que pede uma dedicação temporal muito longa e na maioria dos casos os professores saem de sua cidade para construir carreira nas IFES que existam em qualquer estado do país, como relatam os professores e foi observado pela pesquisadora, os professores afirmaram mudar-se de sua cidade natal para Arapiraca ao assumirem o cargo, para não ficar na estrada a maioria do tempo, tempo este que poderiam estar com família.

Sabe-se que ao assumir o papel de professor-gestor existe uma expectativa de que o indivíduo aceite as novas responsabilidades e que lidem com os desafios do papel de gestor. Nesse sentido, os dados da pesquisa em Arapiraca alinham-se a estudos realizados em outras instituições IFES.

Ao serem questionados sobre o andamento de suas atividades depois de assumirem o papel de gestor na instituição, poucos entrevistados afirmaram que não mudaram em nada em sua rotina de trabalho, como está transcrito abaixo:

$\mathrm{Na}$ realidade eu não deixei de fazer nada, continuo em sala de aula, continuo pesquisando, continuo orientando, continuo fazendo a parte administrativa, enfim, o tempo ele existe e existe para que a gente trabalhe. (PG1).

Assim, note-se que os entrevistados deixam claro que não deixaram de exercer sua atividade de professor, apenas acrescentaram a atividade de gestor, o que sinaliza uma sobrecarga de trabalho, inclusive citada pelo PG2 quando pontua a necessidade de criar equipes de coordenadorias de apoio.

As colocações feitas pelos entrevistados confirmam que o professor-gestor acaba assumindo as atividades dos dois papéis (docente e gestor). De fato, na UFAL/Campus Arapiraca, semelhante a outras IFES, é comum, somarem-se às atividades de ensino, pesquisa e extensão as atividades de gestão universitária, e, portanto, muito raramente o professor abre mão de suas atividades tidas como principais para dedicar-se mais exclusivamente às funções de gestor, como também se observou no trabalho de Silva (2012).

Nota-se também que ao se defrontarem com possível dilema da escolha entre trabalho acadêmico e trabalho administrativo, os entrevistados afirmaram que optaram por não escolher entre os papéis, uma vez que são, primeiramente, docentes professores de formação e que a cadeira de gestão por eles ocupada é temporária. 
Alguns entrevistados quando indagados sobre andamento ou descontinuidade de atividades, mostraram em seu discurso que ocupar uma cadeira de gestão na instituição acarreta mudanças de rotina, desde reorganização de agenda, horários, descontinuidade de algumas atividades, uma vez que eles passam a maior parte do tempo dentro da universidade. O relato a seguir ilustra essa observação:

o que tem pesado em relação a assumir a gestão é a dificuldade que a gente tem de conseguir conciliar os horários principalmente relacionados a pesquisa e extensão. (PG3).

Os aspectos relatados pelos entrevistados ao assumirem o papel de gestão passeiam pelas transições descritas por Silva (2012). Observou-se que as mudanças acontecem por motivo profissional (para assumir um cargo) o que reflete na vida pessoal e faz com que o entrevistado tenha que mudar seus hábitos e até mesmo sua residência.

O PG5, ainda relata como conseguiu reorganizar sua agenda e adequar sua carga horária sem deixar o viés de professor, extensionista, pesquisador e gestor:

[...] a gente faz pesquisa, tem pesquisa sendo feita aqui no nosso campus é.... e a gente não deixou de fazer nenhuma atividade, na verdade a gente só agregou esta. [...] E agora só foi agregada a atividade de pesquisa a essa carga horária e a gente continua fazendo esse trabalho de coordenação (PG5).

Em relação à preparação para assumir o cargo de professor-gestor, as respostas dos professores-gestores da UFAL/Arapiraca foram unânimes, reforçando impressões deixadas por estudos em outras instituições de ensino superior, de que para assumir a gestão o professor não é preparado pela IFES e que a mesma apresenta um nível de complexidade único.

Foi observado nas entrevistas que para assumir o papel de gestor, os professores não contaram com preparação durante sua trajetória de discente na academia ou mesmo no serviço público: "No serviço público, a gente não se prepara pra ser gestor, não tem curso de formação para ser gestor, você chega e você é gestor, então, cada professor ele tem sua nuance de trabalho" (PG1); "Não existe dentro da instituição, pelo menos da nossa, nenhum procedimento, nenhum processo que contribua para preparar o professor a assumir o cargo" (PG3).

Apenas um professor afirmou que sua graduação ajudou a formar seu perfil gestor, por esta trazer em sua grade disciplinas do eixo da gestão: "eu tive a sorte, da minha formação inicial ele te dá um perfil próximo, de você ter uma noção de recurso humano, de preparo de 
recurso humano, de empreendedorismo, de relações pessoais e etc. A minha formação, ela já me forneceu isso, mas ainda você precisa ter o incremento" (PG5).

Levando-se em consideração os discursos citados acima e o fato dos PGs relatarem que não houve preparação para assumir o cargo de gestão, pode-se então concordar que, para desempenhar o papel de professor-gestão, tais sujeitos não passaram por treinamento formal. Isto faz com que esses indivíduos adquiram condições de atuar como gestores, pelo método da tentativa e do erro, - "nós entramos e aprendemos no transcorrer do processo mesmo" (PG3).

Tomado conhecimento da trajetória e dos professores até a gestão a próxima seção tratará das atividades e expectativas que compõe o papel de gestor na visão dos professores entrevistados da UFAL/Campus Arapiraca.

\subsection{ATIVIDADES E EXPECTATIVAS DO PAPEL DE PROFESSOR-GESTOR: O PAPEL PERCEBIDO}

Os papéis sociais desempenhados em qualquer organização deliberam algumas expectativas e atividades; não é diferente com o papel desempenhado pelo professor-gestor. Espera-se que as pessoas que atuam nesse tipo de papel consigam enxergar sua dimensão e perceber o que de fato se espera diante da sua atuação.

Acerca de papel percebido, ao serem questionados sobre esse aspecto, os PGs associam o papel de gestor a desafios de naturezas diversas como percebe-se que para cada um deles a ótica da dificuldade é diferente, como se observa nos trechos das entrevistas a seguir:

Todos, porque fazer gestão é você está cotidianamente mudando, descobrindo, analisando, então assim, cada situação é uma situação diferenciada (PG1).

[...] não ter uma preparação prévia [...] A dificuldade maior mesmo é questão de gerir pessoas (PG3).

Observa-se que os desafios associados ao papel de gestor citados pelos entrevistados se aproximam daqueles apontados por Bergue (2014), eles se permitem conhecer o novo, enfrentar o desafio da gestão, mesmo sem haver preparo e conhecimento para exercer tal papel.

O próximo ponto questionado aos professores-gestores foi sobre o significado para eles de ser professor-gestor, ficou claro para a pesquisadora que a docência não deixou de ser o foco de cada um dos entrevistados: 
Primeiro, eu não sou gestor, sou professor. Sou professor por opção de vida, esse é o motivo maior do professor [...], eu fiz concurso para ser professor, a gestão, ela me caiu como um desafio (PG1).

Os discursos mostram ainda que não existe uma unanimidade da parte dos professores para imprimir o significado de ser professor-gestor, o que permite dizer, diante de tais declarações que o significado não é único porque se tratam de pessoas diferentes com trajetórias distintas. Assim, para darem um significado os professores atribuem expressões como

E o significado foi de que a gente teve crescimento, a gente ganha conhecimento nessa área de gestão (PG2)

Significa infelizmente, que nós temos que fazer a universidade andar (PG4).

Apesar das dificuldades encontradas os professores transmitem em suas falas que estão satisfeitos em assumir o papel de gestor, que o conhecimento adquirido nesse desafio ajuda a crescer em sua vida profissional - "E o significado foi de que a gente teve crescimento, a gente ganha conhecimento nessa área de gestão" (PG2).

Buscou-se ainda saber quais as principais atividades que compõem o papel de professor-gestor na UFAL/Campus Arapiraca. Os discursos mostram aproximações entre si, pois todas as atividades desempenhadas são de cunho administrativo, como se observa no trecho abaixo:

Referente a direção acadêmica é justamente relacionado com dar um suporte para o andamento dos cursos, tanto no aspecto de suporte pedagógico, a questão das relações justamente com o sistema acadêmico, suporte aos professores e colegiados de curso (PG4).

As ações dos professores mostram que o Art. $3^{\circ}$ do Decreto $n^{\circ} 94.664$ de 23 de julho de 1987, que prevê em seu conteúdo que o professor de ensino superior tem que assumir atividade acadêmica e atividade de gestão, vem sendo vivenciado pelos entrevistados, mas ainda com algumas limitações pela estrutura da instituição que ainda não tem autonomia para tomar decisões e se reporta a unidade central a UFAL /Campus A. C. Simões em Maceió.

Em relação ao papel percebido de professor-gestor, os entrevistados foram questionados sobre o que se espera de sua atuação e verificou-se que as falas dos mesmos se aproximam da visão de Barbosa, Cassundé, Mendonça, (2015) ao descreverem-no como sendo o de atender as necessidades e expectativa de vários atores, incluindo estudantes, pares, sociedades, membros de colegiados, entre outros, deixando claro que o cargo de gestão é temporal: 
são duas visões, acho que quem ta de fora sempre tem a expectativa que o gestor tenha capacidade e condições de resolver, [...] de minimizar as dificuldades [...] Mas no momento que a gente assume a gestão, a gente percebe que muitas das nossas ações elas estão presas a todo um trâmite burocrático(PG3).

Que administre bem, porque ele volta a ser professor e o que ele fizer como gestor vai respingar nele (PG2).

Como também, em todos os discursos há elementos que nos permite identificar que o professor da IFES se torna responsável não somente pelos seus alunos ou suas pesquisas; ocupar um cargo de gestão implica também a coordenação de seus pares e regulação de conflitos, entre outras responsabilidades.

Os dados coletados mostram ainda a ausência de dispositivos na forma de decretos, leis, diretrizes, regulamentos, legislação que ajudem a definir o papel de professor-gestor, afirmam os professores:

Não existe hoje, pelo menos que eu tenha conhecimento de uma legislação direta para esse tipo de atividade (PG1).

eu sinceramente desconheço, pelo menos aqui com quem eu converso a gente tem aprendido na prática mesmo, no dia a dia(PG3).

Assim fica claro que os professores têm uma dificuldade para definir o papel de professor-gestor por não haver direcionamento da instituição sobre o que se espera para o papel de gestor.

De fato, a construção do papel não acontece de forma totalmente individual e livre. Importa esclarecer que alguns entrevistados citaram a Lei 8112/90, a Lei 9394/96, e o Art. $3^{\circ}$ do Decreto $n^{\circ} 94.664$ de 23 de julho de 1987, mas apontaram que tais dispositivos não se referem especificamente ao papel de professor-gestor.

Assim, pode-se observar que os professores-gestores da UFAL/Campus Arapiraca também vivenciam a improvisação nas ações de gestão, o imediatismo, assumem o cargo por está previsto em leis que regem o funcionalismo público:

Por exemplo, nesse sentido nós temos algumas resoluções, que você não pode, eu sou Dedicação Exclusiva (DE), então o professor que é DE ele tem que assumir vários cargos, várias funções dentro da universidade (PG4).

O conhecimento de legislação que eu tenho está mais focado em legislação, aquela patrimonial. [...] Mas não existe uma norma que eu conheça sobre papel de professor gestor dentro da instituição, ou que delineei meu trabalho não (PG5). 
Pode-se dizer que, do ponto de vista dos entrevistados, que o papel de professor-gestor na UFAL/Campus Arapiraca está diretamente ligado ao desenvolvimento da universidade através de alocação de recursos, mediação de conflitos, planejamento estratégico, sendo que cada interação feita pelos professores-gestores é de grande importância para a construção do papel que desempenham.

Diante do conhecimento das atividades e expectativas do professor-gestor, a seção seguinte analisará quais grupos contribuem para definição do professor-gestor.

\subsection{CONSTRUÇÃO DO PROFESSOR-GESTOR NA UFAL/CAMPUS ARAPIRACA}

Os entrevistados conseguiram imprimir um conceito de que o professor-gestor não tem uma preparação para o cargo:

No serviço público, a gente não se prepara para ser gestor, não tem curso de formação para ser gestor, você chega e você é gestor (PG1).

A preparação ela se dá a partir do momento que a gente assume a gestão, $[\ldots]$ nós entramos e aprendemos no transcorrer do processo mesmo (PG3).

Diante de tal visão impressa pelos entrevistados, é possível entender que a construção do professor-gestor na UFAL/Campus Arapiraca é um processo contínuo, que se dá diante do andamento dos processos e contato com pessoas que estão por mais tempo na gestão:

[...] a gestão central do Campus Maceió, com as pró-reitorias, com as comissões existentes, então há uma diversidade muito grande de grupos e em que a gente tem essa interlocução diária, frequente e de forma regular. [...] mas essa interlocução de certa forma, principalmente que já são gestores há mais tempo, nos dão um suporte, uma orientação para que a gente possa na própria prática ir aprendendo a errar menos (PG3).

Pode-se observar também que os professores entrevistados apesar de construírem o papel de gestor no dia a dia, no realizar das obrigações, também procuram agir sempre dentro da legislação como já relatado, atendendo as exigências da Lei 8112/90, da Lei 9394/96, e do Art. $3^{\circ}$ do Decreto $n^{\circ} 94.664$ de 23 de julho de 1987, mas ressaltam que não há nenhuma lei ou decreto que delineie seu papel dentro da IFES:

Porque também não há dentro da legalidade uma determinação que trace esse perfil, por ser um cargo eletivo (PG5).

Entretanto, assume-se que os grupos internos também devam participar de alguma forma e em algum nível, desse processo de construção do papel de professor-gestor na UFAL. 
Sendo assim, na próxima seção buscar-se-á elucidar como tais grupos contribuem para a definição do papel de professor-gestor.

\subsection{GRUPOS E A DEFINIÇÃO DO PAPEL DE PROFESSOR-GESTOR}

Procurou-se conhecer os grupos que interagem com os PGs entrevistados, assim também entender como eles influenciam na construção do papel e na atuação de gestor de cada um deles. Nesse sentido, as entrevistas evidenciaram que os cargos ocupados pelos gestores os proporcionam uma vivência com grupos internos e externos da sociedade acadêmica e civil.

Levando em consideração as respostas, pode-se verificar que os professores-gestores da UFAL/Campus Arapiraca interagem com diversos grupos sociais, incluindo estudantes, membros de colegiado, técnicos, pares. Tais interações na maioria dos casos, incidem na construção do papel de professor-gestor, semelhante ao que foi encontrado no trabalho de Barbosa, Cassundé, Mendonça (2015). Os trechos a seguir ilustram essa reflexão:

Eu agi principalmente com os técnicos administrativos e com os alunos (PG2).

Na realidade, frequentemente quem submete trabalhos pra coordenação de extensão, cadastro de projetos, [...] os próprios docentes (PG5)

É, aqui a gente tem uma interação total [...] com grupos de alunos, grupo de professores, com colegiados de curso, com a direção geral [...] uma interlocução boa com a Prefeitura de Arapiraca, [...] dos municípios circunvizinhos (PG3).

Encerrada a apresentação e discussão dos dados coletados, a seguir apresentam-se as considerações finais do presente trabalho.

\section{CONSIDERAÇÕES FINAIS}

Retomando os aspectos introdutórios, a presente pesquisa teve a seguinte pergunta norteadora: como se caracteriza o papel do professor-gestor na Universidade Federal de Alagoas (UFAL)/Campus Arapiraca? Para responder tal questionamento buscou-se identificar a trajetória do professor até sua chegada a gestão; as expectativas e atividades que compõem o papel do professor-gestor na UFAL/ Campus Arapiraca; os principais grupos que contribuem para a definição do papel de professor-gestor; o processo de construção do professor-gestor na UFAL/Campus Arapiraca. 
Para tanto, em relação ao delineamento da pesquisa, desenvolveu-se uma pesquisa qualitativa e exploratória (GIL, 2008). A investigação teve como lócus a Universidade Federal de Alagoas/Campus Arapiraca, situada no agreste do estado de Alagoas, criada em 2006 através do REUNI. Na escolha dos participantes da pesquisa, buscou-se encontrar aqueles capazes de desenvolver uma relação com o fenômeno em estudo. Sendo assim, o grupo de participantes é composto por professores-gestores de nível estratégico da gestão do Campus Arapiraca. Para coleta de dados foram realizadas cinco entrevistas semiestruturadas no mês de março/2016. As categorias do estudo foram definidas a priori, assim como, a técnica de análise dos dados coletados foi a análise categorial sugerida por Bardin (2011).

Os dados analisados concordam com aspectos dos estudados nas pesquisas de Barbosa (2015), Campos (2007), Silva (2012), mostrando que a trajetória acadêmica do professor é longa e que muitas vezes para assumir a gestão o professor precisa deslocar-se, abdicar de algumas atividades acadêmicas e/ou convívio com a família e até mesmo diminuir seu tempo de descanso, e ainda que os professores não são preparados para serem gestores, apenas assumem o cargo. Assim, semelhante ao apontado por Silva (2012), podemos concluir que o professor passa por transições, que são: a mudança por motivo profissional e mudança na vida pessoal.

Sobre as expectativas e atividades que compõem o papel do professor-gestor na UFAL/Campus Arapiraca, os dados estudados e analisados corroboram a ótica de Halles (2005) e Bergue (2014) quando se trata de percepção de papel de professor-gestor diante dos desafios, uma vez que não há preparação para assumir o cargo. Os relatos mostram que os professores se permitem a experiência e a ação.

Quanto ao significado de ser professor-gestor pôde-se concluir que ele não é único, cada professor imprime sua identidade e seu sentimento no papel e acerca das atividades desempenhadas na atividade de gestão os dados mostram que são de cunho administrativo e de ensino-pesquisa-extensão relativas a atividade de docente, e que todos atendem ao Art. $3^{\circ}$ do Decreto ${ }^{\circ} 94.664$ de 23 de julho de 1987, que prevê que o docente de ensino superior tem que assumir atividade acadêmica e de gestão; no que se espera de sua atuação no papel de gestor. Assim, os dados se aproximam dos achados de Barbosa (2015), quando se reconhece a complexidade de atuar no papel e, com Marra (2006) ao se perceber que o professor é responsável por seus alunos, pesquisa e a gestão. 
Em se tratando do processo de construção do professor-gestor na UFAL/Campus Arapiraca, quando os professores afirmam que constroem o papel dia a dia, através de erros e acertos e com as dificuldades encontradas no aprendizado administrativo tal percepção alinhase à visão de Berger e Luckmann (2005). Ainda para tal construção, os sujeitos são amparados por gestores com mais tempo na instituição o que nos remete ao pensamento de Meyer Jr (2003).

Quanto aos principais grupos que contribuem para a definição do papel de professorgestor, as respostas analisadas são semelhantes às do trabalho de Barbosa et al. (2015) quando se observa que para definição e contribuição do papel de professor-gestor há uma interação com todos os principais grupos que auxiliam a UFAL/Campus Arapiraca a atingir seu objetivo principal, incluindo aqui grupos externos, sendo que cada interação feita pelos professores-gestores é de grande importância para a construção do papel que desempenham.

Assim, respondendo à pergunta de pesquisa, pode-se afirmar que o papel de professorgestor na UFAL/Campus Arapiraca caracteriza-se pelas mudanças com motivos profissionais e na vida pessoal para assumi-lo, pelos desafios diários enfrentados por não terem preparação adequada para gestão e pela lacuna de normativas que definam o papel de professor-gestor. Como também, ressalta-se que esse papel se caracteriza por ser uma construção cotidiana que se dá entre erros e acertos, com suporte de grupos que interagem com os gestores.

Diante dos aspectos até aqui apresentados, espera-se que a investigação realizada tenha contribuído com UFAL, mostrando as características do papel de professor-gestor e as dificuldades encontradas pelos sujeitos ao assumirem a gestão. Reconhece-se que o trabalho ora apresentado encontrou algumas limitações como o tempo para investigar o tema proposto, pois poderiam ter sido realizadas entrevistas teste, para melhor aproveitamento dos dados e questionamentos. Ou ainda, foi pesquisado apenas professores-gestores de nível estratégico, se houvesse mais tempo a pesquisa teria sido ampliada com coordenadores de curso, por exemplo.

Como sugestões de pesquisas futuras, seria interessante que a pesquisa seja desenvolvida em outras unidades da UFAL para conseguir traçar o perfil do professor-gestor da instituição, ou em IFES de perfil semelhante a Campus Arapiraca, buscando encontrar aproximações e afastamentos quando do estudo desse papel.

Por fim, apesar do trabalho se preocupar em caracterizar o professor-gestor, assume-se que essa é uma discussão que não será esgotada num futuro próximo. O papel protagonizado 
por professores de ensino superior na gestão universitária mostra que esse é um tema profícuo e que demanda mais estudos como forma de continuar contribuindo para a perenidade dessas instituições tão importantes para a sociedade brasileira - as IFES.

\section{REFERÊNCIAS}

ANASTASIOU, L.G.C; CAVALLET, V.J; PIMENTA, S.G. Docência no ensino superior:construindo caminhos. In: BARBOSA, R.L.L (Org.). Formação de educadores: desafios e perspectivas. São Paulo: UNESP, 2003, p. 267-278.

BARBOSA, M.A.C; CASSUNDÉ, F.R; MENDONÇA, J.R.C. A Interação entre o Papel de Professor-gestor e Competências Gerenciais: percepções dos professores de uma universidade federal. Colóquio de Gestão Universitária: Desafio da Gestão Universitária no Século XXI, Mar Del Plata- Argentina, 2015.

BARBOSA, M.A.C.; A Influência das Políticas Públicas e Políticas Organizacionais Para Formação de Competências Gerenciais no Papel de professor-gestor no Ensino Superior: um estudo em uma IES Federal. 2015. Tese (Doutorado em Administração), Universidade Federal de Pernambuco, UFPE, Brasil, 2015.

BARDIN, L. Análise de conteúdo. São Paulo: Edições 70, 2011.

BAUER, W. M.; GASKELL, G; Pesquisa qualitativa em texto, imagem e som: um manual prático. Tradução: Pedrinho A. Guareschi. Petrópolis, RJ: vozes 2002.

BERGER, P. L.; LUCKMANN, T. A construção social da realidade: tratado de sociologia do conhecimento. 25 Ed. Petrópolis: Vozes, 2005.

BERGUE, S. T. Gestão de estratégica de pessoas no setor público. São Paulo: Atlas, 2014.

BRASIL.Decreto $n^{\circ} 94.664$ de 8 de junho de 1987. Aprova o plano único de classificação e retribuição de cargos e empregos de que trata a Lei no ${ }^{\mathbf{7}}$.596, de 10 de abril de 1987.

Disponível em: $<$ http://www.planalto.gov.br/ccivil_03/decreto/Antigos/D94664.html $>$. Acesso em: 19/12/2015.

CAMPOS, D. C. S. Competências gerenciais dos pró-reitores em uma instituição de ensino superior: um estudo de caso na Universidade Federal de Viçosa. Dissertação (Mestrado em Administração). Minas Gerais: Universidade Federal de Viçosa, 2007. Disponível em:

$<\underline{\text { http://www.locus.ufv.br/bitstream/handle/123456789/2003/texto } \% 20 \text { completo.pdf?sequence }}$ $=1 \&$ isAllowed $=\mathrm{y}>$. Acesso em 21/01/2015 as 11:44.

CARDOSO, G.M.P.; FIGUEIREDO, W.N.; Universidade e sociedade: o papel do professor na (re)construção do conhecimento. Revista Intersaberes | vol. 8, n. 15, p. 36-49| jan. - jun. 2013. 
CASTRO, D.; TOMÀS, M. Development of Manager-Academics at Institutions of Higher Education in Catalonia. Higher Education Quarterly, v. 65, n. 3, p. 290-307, 2011.

CERVIGICELE, G.M.; SOUZA, R. Gestão democrática e formação de gestores no ensino superior: quais as necessidades para a o exercício na coordenação de colegiado de curso? In: XIII Coloquio de Gestión Universitária em Américas. Anais... Buenos Aires: INPEAU, 2013.

ÉSTHER, A. B.; MELO, M. C. O. L. A construção da identidade gerencial dos gestores da alta administração de universidades federais em Minas Gerais. Cadernos EBAPE.BR, v. 6, n.1, p. 01-17, 2008.

ÉSTHER, A. B. As competências gerenciais dos reitores de universidades federais em Minas Gerais: a visão da alta administração. Cadernos EBAPE.BR, v. 9, p. 648-667, 2011.

FRANCO, M. E. D. P. Comunidade de Conhecimento, Pesquisa e Formação do professor de Ensino Superior. In: MOROSINI, M. (Org.). Professor do Ensino Superior: Identidade, Docência e Formação. Volume 1. Porto Alegre: INEP, 2000. p. 61-73.

GASKELL, G. Entrevistas individuais e grupais. In: BAUER, Martin W.; GASKELL, George. Pesquisa qualitativa com texto, imagem e som: um manual prático. $8^{\mathrm{a}}$ Ed. Petrópolis, RJ: Vozes, 2010. p. 64-89.

GIL, A.C. Métodos do Estudo de Caso. Administração On-line. Fundação Escola de Comércio Álvares Pentaeado- FECAP, 2008.

HALES, C. Managerial roles. In: COOPER, Cary L. The blackwell encyclopedia of management. Oxford: Blackwell Publishing. $2^{\mathrm{a}}$ Ed. 2005.

LAVILle, C; DiOnNE, J. Manual de Metodologia da Pesquisa em Ciências Humanas. Adaptação: Lana Mara. Tradução: Heloísa Monteiro e Settineri. Porto Alegre: UFMG, 1999.

MARRA, A. V. O Professor- gerente: processo de transformação. Revista de C. Humanas, Vol. 6, No 2, p. 253-265, Jul./Dez. 2006

MENDONÇA, J. R. C.; PAIVA, K. C. M.; PADILHA, M. A.; BARBOSA, M. A. C. Competências Profissionais de Professores do Ensino Superior no Brasil: proposta de um modelo integrado. In: Fórum da Gestão do Ensino Superior nos Países e Regiões de Língua Portuguesa, 2012, Macau, China. Anais... Macau, China: Instituto Politécnico de Macau, 2012.

MEYER Jr. V. Novo contexto e habilidades do administrador universitário. In: MEYER $\mathrm{Jr}$.

V.; MURPHY, J. P. (Orgs.). Dinossauros, Gazelas e Tigres: novas abordagens da administração universitária. Um diálogo Brasil e Estados Unidos. $2^{\mathrm{a}}$ Ed. Florianópolis: INSULAR, 2003, p. 173-192. 
PACHANE, G. G.; PEREIRA, E. M. A. A importância da formação didático-pedagógica e a construção de um novo perfil para docentes universitários. Revista Iberoamericana de Educación, n. 33, v. 1, 1-13, 2004.

PAIVA, K. C. M. Gestão de competências e a profissão docente um estudo de caso em universidades no Estado de Minas Gerais. 2007. 278f. Tese (Doutorado em

Administração), Universidade Federal de Minas Gerais, Belo Horizonte, Brasil, 2007.

SCHWANDT, T. A. The SAGE dictionary of qualitative inquiry. 3. ed. Thousand Oaks, CA: SAGE Publications, 2007.

SILVA, F. M. V. A transição para a gestão universitária: o significado das relações interpessoais. R. Adm. FACES, v. 11, n. 4, p. 72-91, 2012.

SILVA, F. M. V.; CUNHA, C. J. C. A. A transição de contribuidor individual para líder: a experiência vivida pelo professor universitário. Revista GUAL, Florianópolis, v. 5, n. 1, pp. 145-171, jan./fev./mar./abr. 2012

SILVA, M. G. R. Gestão universitária, competências gerenciais e seus recursos: um estudo de caso. In: Encontro Nacional dos Programas de Pós-Graduação em Administração, 27., 2003, Atibaia. Anais... Atibaia: ANPAD, 2003.

WHITCHURCH, C. Reconstructing identities in higher education: The rise of "Third Space" professionals. London: Routledge, 2012. 